\title{
Awareness of Saudi community toward multiple sclerosis in Qassim Region, Saudi Arabia
}

Nourah A. Al-Hamdan, MD, Eman A. Al-Otaibi, MD, Manal A. Al-Mutairi, MD, Malak G. Al-Mutairi, MD, Ola A. Al-Otaibi, MD, Marwah A. Al-Mozeri, MD, Weam K. Al-Masaud, MD, Manal A. Al-Batanony, MD, PhD.

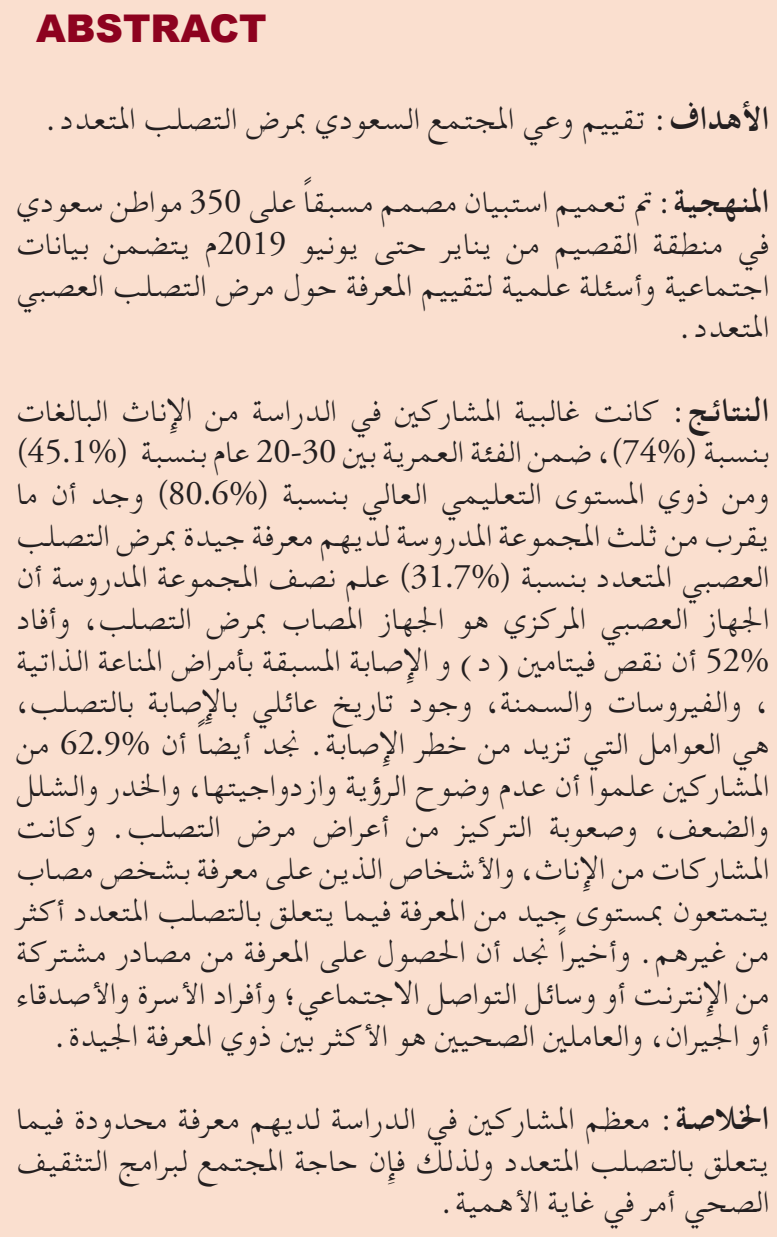

Objectives: To evaluate the awareness of Saudis in Qassim region, Saudi Arabia on multiple sclerosis (MS).

Methods: A cross-sectional study was conducted on 350 Saudis in Qassim, Saudi Arabia between January 2019 and June 2019 using a pre-designed questionnaire including socio-demographic data and questions evaluating knowledge about MS.
Results: The majority of studied participants were adult females (74\%), between 20 -30 year-old $(45.1 \%)$ and with high education level or above (80.6\%). Nearly one third of the studied group had good knowledge regarding MS (31.7\%). Half of the studied group knew that central nervous system (CNS) is the system affected by MS, $52 \%$ reported that vitamin $\mathrm{D}$ deficiency, family history of MS, personal history of autoimmune disease, viruses, and obesity are the factors which increase the risk of developing MS. Approximately, $62.9 \%$ knew that blurred and double vision, numbness, paralysis or weakness and difficulty in concentration and memorizing are symptoms of MS. Female participants and those knowing someone having MS had a significant good knowledge level regarding MS than others. Getting knowledge from combined sources from internet or social media; family, friends or neighbors and health workers was significantly more prevalent among those with good knowledge.

Conclusion: Most of the study participants had limited knowledge regarding MS. Planning health education programs for the public is essential.

$$
\begin{aligned}
& \text { Neurosciences 2021; Vol. } 26 \text { (1): 77-84 } \\
& \text { doi: 10.17712/nsj.2021.1.20200115 }
\end{aligned}
$$

From the Department of Internal Medicine (Al-Hamdan), Department of Family and Community Medicine (Al-Otaibi E, Al-Batanony) Medical Intern (Al-Mutairi MA, Al-Mutairi MG, Al-Otaibi O, Al-Mozeri, Al-Masaud), Unayzah College of Medicine \& Medical Sciences, Qassim University, Buraydah, Kingdom of Saudi Arabia; and from the Department of Community Medicine and Public Health (AlBatanony), Faculty of Medicine, Menoufia University, Egypt.

Received 15th July 2020. Accepted 3rd October 2020.

Address correspondence and reprint request to: Dr. Nourah $A$. Alhamdan, Department of Internal Medicine, Unayzah College of Medicine \& Medical Sciences, Qassim University, Buraydah, Kingdom of Saudi Arabia.E-mail:norah.alhamdan@ucm.edu.sa ORCID ID: https://orcid.org/0000-0003-3990-443X 
$M$ ultiple sclerosis (MS) is an inflammatory neurodegenerative disease affecting the central nervous system (CNS). ${ }^{1,2}$ Among middle-aged adults (between 20 and 40 years), MS is considered as one of the main life-long disability chronic neurological causes which causes expressive health care and economic loads. Women are at 3 to 4 folds increased risk to be affected by MS than men. ${ }^{3,4}$ Neurologically, the common manifestations are loss of coordination and balance, visual impairment, weakness, fatigue, numbness, pain, bladder dysfunction, mood changes, and cognitive dysfunction., 5 Multiple sclerosis has a complex pathophysiology. It is widely recommended as an autoimmune disease, and is mediated by autoreactive lymphocytes that cross the blood-brain barrier (BBB) and enter the CNS, causing local inflammation; producing demyelination, gliotic scarring, and axonal loss. ${ }^{7}$ Pathophysiological concepts revealed that exposure to some infectious agents during childhood as well as genetics involvement played a role. ${ }^{8,9}$ Data reported that females were more affected by MS than males due to genetic predisposition. ${ }^{3}$ Increased risk of MS was related to some environmental factors like obesity, smoking, and low level of vitamin D. ${ }^{10}$ It was reported that breastfeeding for more than 4 months is associated with lower risk for multiple sclerosis. ${ }^{11}$ The etiology of the disease might be related to consanguinity and some local factors. ${ }^{12}$

Recent epidemiological data indicated higher prevalence of MS in Arabian Gulf region, with increasing incidence in Kingdom of Saudi Arabia (KSA). ${ }^{12}$ In the Gulf area, environmental conditions on one side and modulated lifestyle practices in the other side were palmed as associated factors for increasing MS prevalence. ${ }^{12,13}$ The objectives of the first MS multicenter registration in KSA which was carried out between 2015 and 2018 were studying the epidemiology of MS, and its pattern besides studying its clinical findings in the whole country. The result of this registration was alarming and warranted prompt community health actions as it indicated an increasing prevalence of the disease in the whole Kingdom. ${ }^{15}$ Among Saudi nationality the prevalence was $61.95 / 100,000$; whereas between the whole population it was 40.40/100,00016.

According to the available literature, community awareness of MS is generally unacceptable. This affects a person's perception of the disease, delaying the opportunity for early diagnosis and management.

Disclosure. Authors have no conflict of interests, and the work was not supported or funded by any drug company.
Furthermore, it is essential to increase community awareness of MS, as better public understanding of the facts of the disease will engage patients more in the community, and create social activity, education, and employment opportunities. The aim of this study is to evaluate the awareness and level of knowledge regarding MS among the residents of Qassim Region.

Methods. This was a community-based crosssectional descriptive study conducted in the region of Qassim, KSA between January 2019 and June 2019. Qassim region is one of the 13 administrative regions of Saudi Arabia. Located in the center of the country and occupying $3.7 \%$ of the total area of KSA. According to the report of the Saudi General Authority of Statistics in 2017, the population has reached $1423935 .{ }^{16}$ Its capital city is Buraydah, which is inhabited by approximately $60 \%$ of the region's total population.

We used simple random sampling and out of the 11 cities in Qassim Region, we selected the main cities which are Buraydah, Unaizah, and Alras.

The inclusion criteria were Saudi adults aged $\geq 18$ years who agreed to participate in the study. The exclusion criteria were employment as a health-related professional or study at any health college and patient diagnosed of MS.

The participants were interviewed randomly in different public areas in the selected cities, including shopping malls, coffee shops, social clubs, and supermarkets using a convenience non-probability sample. A total of 350 participants were interviewed and all were included in the study. Data were collected using a previously validated questionnaire after taking consent from the original authors. ${ }^{17}$ The questionnaire was divided into 3 sections: A) The participants' sociodemographic characteristics, including age in years, gender, education level, employment, and marital status. B) The participants' sources of information on MS, such as the internet or social media; family, friends, or neighbors; health care workers; or other sources (education programs on TV or radio, and MS information leaflets, brochures, or posters). C) The participants' knowledge of MS. The questionnaire contained 8 Arabic close-ended questions on the system affected by MS, the most common age group and gender affected by MS, the cause and risk factors increasing the risk of developing MS, the symptoms of MS, the presence of a cure, and the presence of medications that can control MS symptoms. The answers to each question were coded as correct (scoring 1 point) or wrong (scoring 0 points). The correct answers for all 8 questions were summed for each participant. A participant was deemed 
to have good knowledge if they answered $\geq 5$ questions correctly; answering $<5$ questions correctly indicated poor knowledge. The cut off was selected based on agreement between $2 \mathrm{MS}$ experts and 2 statisticians to represent the level of knowledge, precisely.

Internal consistency was assessed with Cronbach's alpha ${ }^{18}$ which was found to be 0.81 . Additionally, the questionnaire was pretested in a pilot study on a sample of 35 participants, whose results are not included in the present study. The questionnaires were completed via face-to-face personal interviews with the participants after the purpose of the study had been explained and after their informed written consent had been obtained.

The sample size was calculated using EPI Info ${ }^{\mathrm{TM}} 717$. We used a 95\% confidence interval and 5\% margin of error, and $30 \%$ prevalence of awareness of MS as in the literature. The estimated sample size was 325 , and was adjusted to 350 to compensate for incomplete forms.

Relevant approval for the study was obtained from the Qassim Region Research Ethics Committee. All participants were volunteers and had the right to withdraw from the interview at any point; and the principles of the Declaration of Helsinki were followed. All data were kept confidential and used only for research purposes.

Statistical analysis. The IBM-compatible personal computer with Statistical Package for the Social Sciences, version 20 Windows (IBM Corp, Armonk, NY, USA) was used for data tabulation and statistical analysis. Number and percentage were used to express qualitative data, where Chi-square $(\chi 2)$ test was performed to test comparison between groups. $P$-value $<0.05$ was considered significant.

Results. The majority of participants were women (74\%), aged $20-30$ years (45.1\%), with high education level or above (80.6\%), employed (59.1), married (54.9\%), and from Buraydah (40.6\%). The most frequent source of information on MS was the Internet or social media $(35.7 \%)$, followed by the combined sources of the Internet or social media; family, friends, or neighbors; and health care workers $(25.4 \%)$; and family, friends, or neighbors (20.9\%) (Table 1). Nearly one-third of the participants $(31.7 \%)$ had good knowledge of MS, whereas $68.3 \%$ had poor knowledge of the disease (Figure 1). Frequency distribution of the knowledge questions showed that $50 \%$ of the participants knew that MS affects the CNS; $40.6 \%$ stated that 20-40-year-olds are the most common age group affected; $38.6 \%$ stated that women are more likely to develop MS than men; $15.4 \%$ identified MS as being of unknown etiology; $52 \%$ stated that vitamin
D deficiency, family history of MS, personal history of autoimmune disease, viruses, and obesity as the factors that increase the risk of developing MS; $62.9 \%$ knew that blurred and double vision, numbness, paralysis or weakness, and difficulty concentrating and remembering are symptoms of MS; $19.4 \%$ stated there is no cure for MS; and $50.6 \%$ agreed that medications can control the disease. The female participants had significantly higher MS knowledge levels than the male participants $(p=0.02)$. Obtaining knowledge from combined sources

Table 1 - Characteristics of the studied population.

\begin{tabular}{|c|c|}
\hline Characteristics & n $\quad(\%)$ \\
\hline \multicolumn{2}{|l|}{ Age group (in years) } \\
\hline 20 & $158(45.1)$ \\
\hline 30 & $123(35.1)$ \\
\hline $40-57$ & $69(19.7)$ \\
\hline \multicolumn{2}{|l|}{ Gender } \\
\hline Male & $91(26.0)$ \\
\hline Female & $259(74.0)$ \\
\hline \multicolumn{2}{|l|}{ Education level } \\
\hline Secondary and less & $68(19.4)$ \\
\hline High and above & 282 (80.6) \\
\hline \multicolumn{2}{|l|}{ Employment } \\
\hline Employee & $207(59.1)$ \\
\hline Unemployed & $143(40.9)$ \\
\hline \multicolumn{2}{|l|}{ Marital status } \\
\hline Single & $159(45.4)$ \\
\hline Married & $191(54.6)$ \\
\hline \multicolumn{2}{|l|}{ Residence } \\
\hline Buraydah & $142(40.6)$ \\
\hline Unaizah & $123(35.1)$ \\
\hline Al-Ras & $85(24.3)$ \\
\hline \multicolumn{2}{|l|}{ Know someone having MSL } \\
\hline No & $268(76.6)$ \\
\hline Yes & $82(23.4)$ \\
\hline \multicolumn{2}{|l|}{ Sources of information on $M S$} \\
\hline Internet or social media & $125(35.7)$ \\
\hline Family, friends or neighbors & $73(20.9)$ \\
\hline Health care workers & $14 \quad(4.0)$ \\
\hline Combined sources ${ }^{*}$ & $89(25.4)$ \\
\hline Others $^{\dagger}$ & $49(14.0)$ \\
\hline \multicolumn{2}{|c|}{$\begin{array}{l}{ }^{*} \text { Combined sources are internet or social media; family, friend } \\
\text { or neighbors and health care workers. }{ }^{\dagger} \text { Others are education } \\
\text { program on TV or Radio, and multiple sclerosis (MS) } \\
\text { information leaflets, brochures or posters. }\end{array}$} \\
\hline
\end{tabular}


Awareness on MS among Qassim community ... Al-Hamdan et al

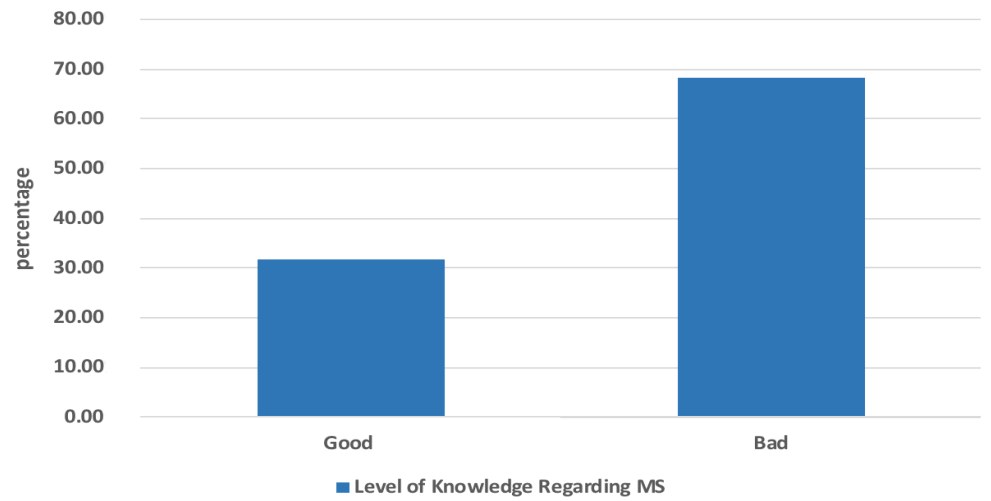

Figure 1 - Knowledge level regarding multiple sclerosis (MS) among studied population.

Table 2 - Frequency distribution of knowledge regarding multiple sclerosis (MS) among studied participants.

\begin{tabular}{|c|c|}
\hline Knowledge questions & n $(\%)$ \\
\hline \multicolumn{2}{|l|}{ 1. Which system is affected by MS? } \\
\hline Incorrect/Don't know & $175(50.0)$ \\
\hline Central nervous system & $175(50.0)$ \\
\hline \multicolumn{2}{|l|}{ 2. Which age group is affected by MS? } \\
\hline Incorrect/Don't know & $208(59.4)$ \\
\hline $20-40$ & $142(40.6)$ \\
\hline \multicolumn{2}{|l|}{ 3. Who is affected more by MS? } \\
\hline Incorrect/Don't know & $215(61.4)$ \\
\hline Females & $135(38.6)$ \\
\hline \multicolumn{2}{|l|}{ 4. What is the cause of MS? } \\
\hline Incorrect/Don't know & $296(84.6)$ \\
\hline Unknown & $54(15.4)$ \\
\hline \multicolumn{2}{|c|}{ 5. What are the factors that increase the risk of developing MS? } \\
\hline Incorrect/Don't know & $168(48.0)$ \\
\hline Correct & $182(52.0)$ \\
\hline Vitamin D deficiency* & $54(29.7)$ \\
\hline Family history of $\mathrm{MS}^{*}$ & $42(23.1)$ \\
\hline Personal history of Autoimmune disease & $41(22.5)$ \\
\hline Viruses ${ }^{*}$ & $29(15.9)$ \\
\hline Obesity $^{*}$ & $16(8.8)$ \\
\hline \multicolumn{2}{|l|}{ 6. What are the symptoms of Multiple Sclerosis? } \\
\hline Incorrect/Don't know & $130(37.1)$ \\
\hline Correct & $220(62.9)$ \\
\hline Blurred and double vision ${ }^{*}$ & $85(38.6)$ \\
\hline Numbness* & 67 (30.6) \\
\hline Paralysis or weakness ${ }^{*}$ & $53(24.1)$ \\
\hline Difficulty in concentration and memorizing & $15(6.8)$ \\
\hline \multicolumn{2}{|l|}{ 7. Is there a cure for Multiple Sclerosis? } \\
\hline Incorrect/Don't know & $282(80.6)$ \\
\hline No & $68(19.4)$ \\
\hline \multicolumn{2}{|c|}{ 8. Is there medications can control multiple sclerosis symptoms? } \\
\hline Incorrect/Don’t know & $173(49.4)$ \\
\hline Yes & 177 (50.6) \\
\hline
\end{tabular}

For question \#5, 182 participants correctly answered this question; the following correct words are the differentiation of those correct answers as vitamin D deficiency, Family history of MS*, Personal history of autoimmune disease, viruses and obesity where the total of those differentiation is from the correct answer (182) as mentioned in the footnote. The same for question number 6 . 
Awareness on MS among Qassim community ... Al-Hamdan et al

Table 3 - Relationship between socio-demographic characteristics of the studied group and their knowledge level regarding multiple sclerosis (MS).

\begin{tabular}{|c|c|c|c|}
\hline \multirow[b]{2}{*}{ Characteristics } & \multicolumn{2}{|c|}{ Knowledge level } & \multirow{2}{*}{$P$-valu } \\
\hline & $\begin{array}{c}\text { Poor } \\
(n=239)\end{array}$ & $\begin{array}{c}\text { Good } \\
(n=111)\end{array}$ & \\
\hline \multicolumn{4}{|l|}{ Age group (in years) } \\
\hline $20-$ & $110(69.6)$ & $48(30.4)$ & \multirow{3}{*}{0.62} \\
\hline $30-$ & $80(65.0)$ & $43(35.0)$ & \\
\hline $40-57$ & $49(71.0)$ & $20(29.0)$ & \\
\hline \multicolumn{4}{|l|}{ Gender } \\
\hline Male & $71(78.0)$ & $20(22.0)$ & \multirow{2}{*}{0.02} \\
\hline Female & $168(64.9)$ & $91(35.1)$ & \\
\hline \multicolumn{4}{|l|}{ Education level } \\
\hline Secondary and less & $47(69.1)$ & $21(30.9)$ & \multirow{2}{*}{0.87} \\
\hline High and above & $192(68.1)$ & $90(31.9)$ & \\
\hline \multicolumn{4}{|l|}{ Employment } \\
\hline Employee & $145(70.0)$ & $62(30.0)$ & \multirow{2}{*}{0.39} \\
\hline Un-employed & $94(65.7)$ & $49(34.3)$ & \\
\hline \multicolumn{4}{|l|}{ Marital status } \\
\hline Single & $106(66.7)$ & $53(33.3)$ & \multirow{2}{*}{0.55} \\
\hline Married & $133(69.6)$ & $58(30.4)$ & \\
\hline
\end{tabular}

Table 4 - Relationship between knowledge level and sources of knowledge regarding multiple sclerosis (MS) and knowing someone having MS.

\begin{tabular}{|c|c|c|c|}
\hline \multirow{2}{*}{ Variable } & \multicolumn{2}{|c|}{ Knowledge level } & \multirow{2}{*}{$P$-value } \\
\hline & $\begin{array}{c}\text { Poor } \\
(\mathbf{n}=239)\end{array}$ & $\begin{array}{c}\text { Good } \\
(\mathrm{n}=111)\end{array}$ & \\
\hline \multicolumn{4}{|c|}{ Sources of information about $M S$} \\
\hline Internet or social media & $87(69.6)$ & $38(30.4)$ & 0.69 \\
\hline Family, friends or neighbors & $55(75.3)$ & $18(24.7)$ & 0.15 \\
\hline Health care workers & $10(71.4)$ & $4(28.6)$ & 0.79 \\
\hline Combined sources* & $52(58.4)$ & $37(41.8)$ & $0.02^{*}$ \\
\hline Others ${ }^{*}$ & $35(71.4)$ & $14(28.6)$ & 0.61 \\
\hline \multicolumn{4}{|l|}{ Knowing someone having MS } \\
\hline No & $191(71.3)$ & $77(28.7)$ & \multirow{2}{*}{$0.03^{*}$} \\
\hline Yes & $48(58.5)$ & $34(41.5)$ & \\
\hline \multicolumn{4}{|c|}{$\begin{array}{l}\text { Values are presented as numbers and percentages }(\%) \cdot{ }^{*} \text { Combined sources are internet or social media; family, } \\
\text { friends or neighbors and health care workers. \#Others are education program on TV or Radio and MS } \\
\text { information leaflets, brochures or posters. Comparison was done between numbers in each row and the rest of } \\
\text { the group. }{ }^{*} \text { significant result }\end{array}$} \\
\hline
\end{tabular}


was significantly more prevalent among those with good knowledge than those with poor knowledge $(p=0.02)$. Moreover, participants who knew a person with MS had significantly better MS knowledge than those who $\operatorname{did}$ not $(p=0.03)$.

Discussion. Multiple sclerosis is an unpredictable, disabling inflammatory disease of the CNS. Greater awareness and education on the disease lead to the better benefits of early recognition and intervention. ${ }^{19}$ Here, we report that the prevalence of good MS knowledge in the Saudi population of Qassim Region in the KSA is $31.7 \%$. This prevalence is in agreement with the prevalence reported in other Saudi studies. A study conducted in Riyadh ${ }^{17}$ involving 226 residents that evaluated MS knowledge showed that $30.3 \%$ of the respondents were aware and had good knowledge of MS. In Al-Taif, KSA, a community-based study involving 715 participants reported 26\% adequate knowledge. On the other hand, the good knowledge prevalence in the present study is much better than that recorded for Majmaah, which was $12.7 \%$ average/good knowledge. Generally, public awareness of MS is poor, and this limited understanding delays early diagnosis and treatment. ${ }^{20-22}$

In the present study, nearly three-fourths of the participants were female. This agrees with the study in Al-Taif, where $65 \%$ of the participants were female. ${ }^{20}$ Despite the low level of knowledge in the present study, half of the participants recognized MS as a neurological disease affecting the CNS. This agrees with Hudaif et $\mathrm{al},{ }^{17}$ who reported a similar percentage of $61 \%$, and was higher than that reported by Amer et al, ${ }^{20}$ which was only $14 \%$. In our study, more than $40 \%$ of the participants knew that younger people, example those aged 20-30 years old, are more affected by MS. Multiple sclerosis is most commonly first diagnosed between the ages of 20 and 40 years; over time, it results in varying levels of progressive mobility and sensory functional limitations affecting not only function but also appearance. ${ }^{23}$

This finding is in line with Hudaif et $\mathrm{al}^{17}$ and better than that of Amer et al. ${ }^{20}$ In the present study, 38.6\% of participants answered that MS affects more women than men, as also reported by Hudaif et $\mathrm{al}^{17}$ and Amer et al. ${ }^{20}$ The Multiple Sclerosis International Federation reported that women and young adults are commonly affected by MS. ${ }^{24}$ The average age of onset of MS is 30 years, which is the age a person typically begins a family and may not have typically reached their full earning potential; MS has a particularly destructive outcome on family, social, and professional relationships. Critical diagnosis and early treatment can prevent the irreversible long-term sequelae in patients with MS. ${ }^{25,26}$
More than half (52\%) of the respondents in the present study answered that vitamin D deficiency, family history of MS, personal history of autoimmune disease, viruses, and obesity were factors that increased the risk of developing MS. This finding is much better than that in the Riyadh, KSA ${ }^{17}$ and Al-Taif, KSA studies. ${ }^{20}$ There is considerable evidence that vitamin $\mathrm{D}$ deficiency may increase susceptibility to MS. ${ }^{27}$ Vitamin D deficiency is present in $28-80 \%$ of Saudi adults. On the other hand, vitamin $\mathrm{D}$ supplementation can eliminate disability. ${ }^{22}$ In addition, adolescent obesity and smoking are considered factors that increase the risk of susceptibility for MS. ${ }^{28}$ As sensory symptoms are the most common presenting symptoms of MS, nearly two-thirds of the participants $(62.9 \%)$ in the present study recognized blurred and double vision, numbness, paralysis or weakness, and difficulty concentrating and remembering as common symptoms of MS. Insufficient or lack of information regarding the symptoms of the disease may be the reason behind the late presentation of patients, who miss the opportunity for better disease outcome. Some trials have revealed that early management is vital for delaying MS development, slowing its progression, and reducing disability. Thus, good MS awareness can lead to early diagnosis and prevent complications. ${ }^{29}$

Moreover, less than one-fifth of the respondents in the present study answered that there is no cure for MS, and $50.6 \%$ stated that medications can control the disease. These results agree with that of Hudaif et al ${ }^{17}$ and Amer et al. ${ }^{30}$

In the present study, we compared respondents with good and bad knowledge on MS according to their sociodemographic characteristics. There was no significant relationship between knowledge level and sociodemographic data except for gender. Female participants had significantly good knowledge of MS compared to male participants. This is in contrast with Hudaif et $\mathrm{al}^{17}{ }^{17}$ who reported no significant gender difference. This could be attributed to some knowledge gained by the public between the timing of the 2 studies, example, 6 years, besides the increasing prevalence of MS in the Kingdom in recent years. ${ }^{15}$ Evidence from epidemiological studies has indicated that the Arabian Gulf region, which is located in a low-risk zone for MS, has a high prevalence of MS, with incidence increasing in Saudi Arabia, suggesting that the move to moderateto-high prevalence is imminent. ${ }^{16}$

In the present study, the participants' most common source of information on MS was the Internet or social media, followed by the combined sources of the Internet or social media; family, friends, or neighbors, and health care workers. Combined sources were significantly more prevalent among the participants with good knowledge 
than those with poor knowledge. This is supported by a significant relation between good knowledge and knowing someone who has MS. It means that when a person knows someone with MS, they would search for a source of information to obtain data on the disease to help their lover. However, Arhan et $\mathrm{al}^{30}$ demonstrated that written materials can be an effective, inexpensive, and easy-to-implement strategy to improve popular understanding of a condition or its treatment, especially for the patient's family.

Our finding is in contrast with that of Hudaif et $\mathrm{al}^{17}$ and Amer at $\mathrm{al},{ }^{20}$ who found that learning from the people around them was a significant source of information on MS among their respondents. Reliance on the Internet or social media; family, friends, or neighbors to obtain MS knowledge may point to a lack of available information on the disease on social media. This is an important issue for governmental and non-governmental organizations to consider a variety of channels for disseminating trustworthy information and learning materials on MS and to communicate information to the public. A reliance on authentic sources is a key factor to believing transparent information. ${ }^{32}$

In the end, helping others better comprehend MS is the basis to spurring the improvement that changes the lives of those affected by the disease, and will eventually improve their lives and bring a permanent end to complications and disability. In this manner, broad popularization should be actualized to bring information about MS to light, with proficient treatment and to diminish the burden. ${ }^{31}$

Study limitation. The study was conducted in one region out of the 11 regions in KSA; therefore, results cannot be generalized to the whole population of Saudi Arabia.

In conclusion, The majority of participants had limited knowledge on MS. This was a known fact from the previous literature. However, in our study we found that the female participants had significantly higher knowledge than the male participants. Also, obtaining knowledge from the Internet or social media; family, friends or neighbors; and health workers was significantly more prevalent among those with good knowledge. In addition, participants who knew someone with MS had significantly higher knowledge levels. Thus, condensed health education programs/campaigns regarding MS for the public via various channels are essential for disseminating transparent information for the early detection and proper management of this devastating disease. Further studies are recommended to clarify the barriers beyond suboptimal knowledge.

\section{References}

1. Calabresi PA. Diagnosis and management of multiple sclerosis. american family physician. Am Fam Physician 2004; 70: 1935-1944.

2. Kasper D, Fauci A, Hauser S, Longo D, Jameson JL, Loscalzo J. Harrison's Principles of Internal Medicine, 19th edition. In ed: Shanahan JK, Davis JKJ. 2015 McGraw-Hill: 2015. p.1013

3. Koch-Henriksen N, Sørensen PS. The changing demographic pattern of multiple sclerosis epidemiology. Lancet Neurol 2010; 9: 520-532.

4. Kurtzke JF. Epidemiology of multiple sclerosis. Does this really point toward an etiology? Lectio Doctoralis. Neurol Sci 2000; 21: 383-403.

5. Wallin MT. Global, regional, and national burden of multiple sclerosis 1990-2016: a systematic analysis for the Global Burden of Disease Study 2016. Lancet Neurol 2019; 18: 269-285.

6. Multiple Sclerosis International Federation. What is MS: MS International Federation. [Updated 2020 September 14. Cited 2020 June 30]. Available from URL: https://www.msif.org/ about-ms/what-is-ms/

7. Trapp BD, Nave KA. Multiple sclerosis: an immune or neurodegenerative disorder?. Annu Rev Neurosci 2008; 31: 247-269.

8. Korn T. Pathophysiology of multiple sclerosis. J Neurol 2008; 255 [Suppl 6]: 2-6.

9. Wingerchuk DM, Lucchinetti CF, Noseworthy JH. Multiple sclerosis: current pathophysiological concepts. Lab Invest 2001; 81: 263-281.

10. Ascherio A, Munger K. Epidemiology of multiple sclerosis: from risk factors to prevention--an update. Semin Neurol 2016; 36: 103-114

11. Conradi S, Malzahn U, Paul F, Quill S, Harms L, Bergh FT, et al. Breastfeeding is associated with lower risk for multiple sclerosis. Mult Scler 2013; 19: 553-558.

12. Mansouri B, Asadollahi S, Heidari K, Fakhri M, Assarzadegan F, Nazari M, et al. Risk factors for increased multiple sclerosis susceptibility in the Iranian Population. J Clin Neurosci 2014; 21: 2207-2211.

13. Bohlega S, Inshasi J, Al Tahan AR, Madani AB, Qahtani H, Rieckmann P. Multiple sclerosis in the Arabian Gulf countries: a consensus statement. J Neurol 2013; 260: 2959-2963.

14. Al Wutayd O, Mohamed AG, Saeedi J, Al Otaibi H, Al Jumah M. Environmental exposures and the risk of multiple sclerosis in Saudi Arabia. BMC neurol 2018; 18: 86.

15. Al-Jumah M, Bunyan R, Otaibi HA, Cupler E, Ishak S, Shami $S$, et al. The Saudi Arabian National Multiple Sclerosis Registry (NMSR): initial results Saudi MS Registry Study Group* (P2.390). Neurology 2018; 90: P2.390.

16. General Authority of Statistics, Population Characteristics surveys 2017. Available from: https://www.stats.gov.sa/sites/ default/files/msh_lkhsys_lskny_2017_.pdf

17. Hudaif HSA, Bwardi NA, Kojan S. Assessment of multiple sclerosis awareness and knowledge among the Saudi population in Riyadh City. Mult Scler Relat Disord 2014; 3: 758.

18. Taber KS. The use of Cronbach's alpha when developing and reporting research instruments in Science education. Res Sci Educ 2018; 48: 1273-1296.

19. Aljumah M, Alroughani R, Alsharoqi I, Bohlega SA, Dahdaleh M, Deleu D, et al. Future of management of multiple sclerosis in the middle East: a consensus view from specialists in ten countries. Mult Scler Int 2013; 2013: 952321. 
20. Amer MG, AlZahrani WA, AlZahrani AA, Altalhi FA, Alrubaie SS, Alsini RA, et al. Assessment of multiple sclerosis awareness: knowledge and attitude among saudi population in Taif City, KSA. Int J Adv Res 2016; 4: 1758-1766.

21. Alotaibi FF. Assessment of knowledge and attitude of women in Majmaah city, Saudi Arabia about multiple sclerosis, 2016. J Neurol Neurophysiol 2016; 7: 74.

22. Derakhshandi H, Etemadifar M, Feizi A, Abtahi SH, Minagar A, Abtahi MA, et al. Preventive effect of vitamin D3 supplementation on conversion of optic neuritis to clinically definite multiple sclerosis: a double blind, randomized, placebo-controlled pilot clinical trial. Acta Neurol Belg 2012; 113: 257-263.

23. Lolli F, Rovero P, Chelli M, Papini AM. Toward biomarkers in multiple sclerosis: new advances. Expert Rev Neurother 2014; 6: 781-794.

24. MSIF Atlas of MS 2013 [Internet]. MS International Federation. [cited 2020Jun30]. Available from: https://www. msif.org/resource/msif-atlas-of-ms-2013/

25. Miller JR. The importance of early diagnosis of multiple sclerosis. J Manag Care Pharm 2004; 10: S4-S11.

26. Yamout BI, Dahdaleh M, Al Jumah MA, Al-Shammri S, Al Sharoqi A, Al-Tahan AR, et al. Adherence to disease-modifying drugs in patients with multiple sclerosis: a consensus statement from the Middle East MS Advisory Group. Int J Neurosci 2010; 120: $273-279$.
27. Kampman MT, Steffensen LH, Mellgren SI, Jørgensen L. Effect of vitamin D3 supplementation on relapses, disease progression, and measures of function in persons with multiple sclerosis: exploratory outcomes from a double-blind randomised controlled trial. Mult Scler 2012; 18: 1144-1151.

28. Hedström AK, Bomfim IL, Barcellos L, Gianfrancesco M, Schaefer C, Kockum I, et al. Interaction between adolescent obesity and HLA risk genes in the etiology of multiple sclerosis. Neurology 2014; 82: 865-872.

29. Gold R, Wolinsky JS, Amato MP, Comi G. Evolving expectations around early management of multiple sclerosis. Ther Adv Neurol Disord 2010; 3: 351-367.

30. AlJumah M, Bunyan R, Al Otaibi H, Al Towaijri G, Karim A, Al Malik Y, et al. Rising prevalence of multiple sclerosis in Saudi Srabia, a descriptive study. BMC neurol 2020; 20: 1-7.

31. Arhan E, Serdaroglu A, Soysal S, Ozcelik A, Gucuyener K, Demir E. Assessment of mothers' knowledge and perceptions of electroencephalography and determination of the short-term effect of an informational leaflet. Epilepsy Behav 2009; 15: 491-495.

32. Bhagavathula AS, Aldhaleei WA, Rahmani J, Mahabadi MA, Bandari DK. Knowledge and perceptions of COVID-19 among health care workers: cross-sectional study. JMIR Public Health Surveill 2020; 6: e19160. 